\title{
A FORMAÇÃO HUMANA POR MEIO DA FORMAÇÃO FILOSÓFICA NO ENSINO MÉDIO
}

\author{
Branca Jurema Ponce ${ }^{1}$ \\ Lívio dos Santos Wogel ${ }^{2}$
}

Resumo: Com o foco no papel formativo da Filosofia no Ensino Médio, o artigo defende que esse componente curricular pode colaborar de modo significativo para a formação humana dos jovens, desde que os estudantes sejam convidados a serem autores, atores e narradores no diálogo que emerge da convivência e que entrelaça as filosofias com as existências presentes, de modo a propiciar o desenvolvimento humano.

Palavras-chave: Filosofia. Educação. Ensino de Filosofia. Ensino Médio. Formação humana.

Resumen: Con el foco en el papel formativo de la filosofía en la escuela secundaria, el artículo sostiene que el componente curricular puede contribuir significativamente para la formación humana de los jóvenes, siempre que los estudiantes sean invitados a convertirse en autores, actores y narradores en el diálogo que surge de la convivencia y que entrelaza las filosofías con la existencia de cada uno, de modo a fomentar el desarrollo humano.

Palabras clave: Filosofía. Educación. Enseñanza de Filosofía. Escuela Secundaria. Formación humana

\section{Introdução}

Com o objetivo de refletir sobre a formação filosófica no Ensino Médio, inicia-se considerando o processo de formação humana na educação escolar. Tendo por princípio que a formação filosófica na escola deve colaborar com a formação humana, apresenta-se, neste artigo, a perspectiva que a Filosofia pode apresentar para o estudante do Ensino Médio.

Com este foco, as reflexões que aqui se apresentam foram inspiradas na pesquisa teórica realizada em nível de doutorado, no Programa de Pós-Graduação

\footnotetext{
${ }^{1}$ Profa. Titular da Pontifícia Universidade Católica de São Paulo. Atua no Departamento de Fundamentos de Educação, no Programa de Pós-Graduação em Educação: Currículo. Email: tresponces@uol.com.br.

${ }^{2}$ Doutor em Educação, Licenciado em Filosofia e professor de filosofia no Instituto Federal de Educação, Ciência e Tecnologia de Mato Grosso - Campus São Vicente. Email: liviowogel@hotmail.com.
}

PONCE, Branca Jurema; WOGEL, Lívio dos Santos. A formação humana por meio da formação filosófica no ensino médio. Revista Sul-Americana de Filosofia e Educação. Número 26: maio-out./2016, p. 133-148. 
em Educação: Currículo, da Pontifícia Universidade Católica de São Paulo, que resultou na tese denominada Filosofia e Ócio: possibilidades de originárias de formação no Ensino Médio, cuja defesa se deu em 2014. Essa tese esteve vinculada ao projeto de pesquisa Políticas curriculares para a educação básica propostas pelo Estado e sua ressonância na prática pedagógica, desenvolvidas entre os anos de 2010 a 2013, coordenada pela profa. Dra. Branca Jurema Ponce.

A pesquisa apontou que os sistemas de ensino brasileiros têm empreendido iniciativas curriculares por meio de duas modalidades básicas: a primeira, por meio de material apostilado/padronizado produzido pelos próprios sistemas públicos de educação; a segunda, pela compra, por parte dos sistemas públicos, de pacotes curriculares de organizações privadas (CHIZZOTTI; PONCE, 2012; CÁRIA, 2012). Apontou, ainda, que os tempos definidos para trabalhar os conteúdos pré-determinados estão longe de serem tempos pedagogicamente considerados (PONCE, 2016). O ponto comum aos estudos dessa pesquisa mais ampla foi a preocupação com o lugar dos sujeitos na implementação dos programas curriculares oficiais, não apenas por entender que o professor é figurachave do processo educativo, mas sobretudo porque a crescente restrição à sua autonomia pedagógica evidencia uma descrença na capacidade intelectual dos professores.

De antemão, apresenta-se que um dos contributos que a Filosofia oferece aos estudantes da Educação Básica e aos profissionais que nela atuam é refletir acerca de uma visão humana que se propõe formar. Como afirmam Lorieri e Rios:

Quando nos envolvemos em um trabalho educativo na escola, temos intenções explícitas: queremos, com os "currículos" que apresentamos, produzir certos efeitos em nossos alunos, para que se tornem seres humanos de algum modo. Um currículo é um "curso de ação educativa", é o próprio "movimento da vida da escola" - realiza-se por meio dos "componentes curriculares" que envolvem as disciplinas $e$ todas as demais atividades programadas e desenvolvidas no interior do contexto escolar e em suas relações com o contexto social amplo. (LORIERI; RIOS, 2004, p.38). 


\section{A formação filosófica no Ensino Médio}

Para o estudante em formação no Ensino Médio - que já passou pelas fases da fundamentação elementar e que agora está no processo final da formação escolar básica em que suas capacidades de abstração e de escolha se encontram em processo de início de maturação - a Filosofia aparece como um contributo para a formação humanística. O estudante nesse nível pode perceber-se e compreenderse como um sujeito de conhecimento e de ação transformadora, tendo o conhecimento filosófico como aliado que suscita a reflexão consciente de si mesmo, ao aprimorar sua capacidade crítica e criativa e a compreensão de si em relação ao mundo. Estas compreensões irão formar a sua identidade de pessoa humana, capaz de se desenvolver, buscar e realizar os projetos que idealiza para si mesma e para o mundo.

O jovem brasileiro em fase de formação básica, ao identificar a si mesmo no feixe de relações que estabelece, deveria, ao final do Ensino Médio, visualizar e agir em busca de conquistar aquilo que almeja para inserir-se criticamente no mundo. É um trabalho de constituição de mais clareza e profundidade da própria subjetividade, algo bastante desafiador para os estudantes que cursam o Ensino Médio.

Severino (2012) é categórico ao apresentar a contribuição formativa da Filosofia nessa etapa escolar:

[...] no caso do ensino médio, pouco importa se o adolescente vai ter a terminalidade de seus estudos nesse nível, inserindo-se já no mundo do trabalho, ou se ele vai para a universidade. Sua formação filosófica é absolutamente necessária para que o adolescente possa se dar conta do significado da sua existência histórica, do significado da inserção dele seja onde for, no mundo do trabalho, no mundo da profissão, no mundo da cultura. (SEVERINO, 2012, p. 16). 
Na mesma direção, Deina (2009, p.132) reflete sobre a contribuição que a presença da Filosofia, no caso específico do Ensino Médio, pode oferecer ao jovem: "Colaborar para o aprimoramento de sujeitos, em pleno processo de formação, numa fase crucial para a definição do sentido da existência".

Em 2 de junho de 2008, a Lei Federal no 11.684, alterou o art. 36, inciso III da Lei de Diretrizes e Bases da Educação Nacional (LDB) de no 9.394, de 20 de dezembro de 1996, acrescentando o inciso IV ao referido artigo 36, incluindo a Filosofia e a Sociologia como componentes curriculares obrigatórios no currículo do Ensino Médio das escolas brasileiras.

As escolas brasileiras tiveram que dar sua resposta à Lei e a comunidade científica respondeu à demanda das escolas com um aumento na produção científica em artigos em periódicos acadêmicos sobre o ensino dessas disciplinas. Em relação ao ensino de Filosofia, coleta feita em periódicos considerados nas quatro categorias mais pontuadas (revistas científicas A1, A2, B1 e B2) pela Coordenação de Aperfeiçoamento de Pessoal de Nível Superior (CAPES), fundação do Ministério da Educação (MEC), revelam que foi

possível observar que houve aumento da produção sobre a temática ensino de filosofia no ensino médio. Há cinco artigos em 2004, ano delimitador do início da pesquisa. De 2004 a 2008, registra-se um total de 15 artigos publicados, o que dá em média 3 artigos por ano. A partir de 2009 até 2013, foram publicados 22 artigos, o que permite afirmar que houve um significativo aumento da produção acadêmica sobre o tema. Observe-se que a promulgação da Lei $n .^{\circ}$ 11.684/2008, que obrigou a inclusão da disciplina no currículo do ensino médio, ocorreu em 2008. (PONCE; MINEIRO, 2015).

Também foi possível observar um maior interesse sobre o tema na produção acadêmica em teses e dissertações brasileiras: 


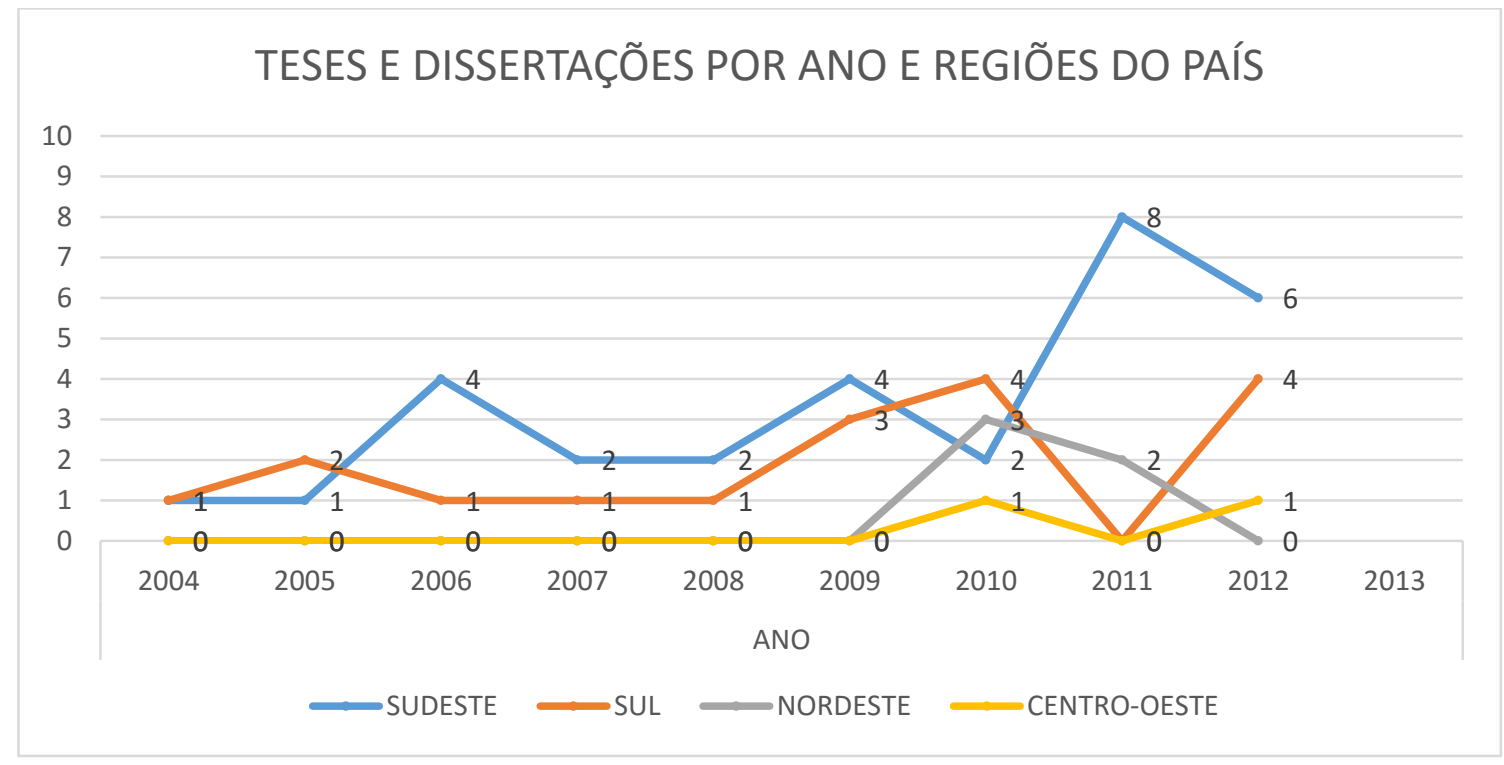

Gráfico 1 - Teses e dissertações - produção por ano/região

Fonte: Mineiro (2015, p. 61).

Constata-se - pelos dados - que houve um aumento da produção de teses e dissertações após o ano de 2008, "confirmando a hipótese de que professores/pesquisadores intensificaram o que já vinha sendo realizado por parte da comunidade acadêmica interessada no debate sobre o ensino de filosofia no ensino médio". (PONCE; MINEIRO, 2015).

Os estudantes do Ensino Médio, com a colaboração das escolas, da produção acadêmica, do conhecimento filosófico que foi inserido de modo obrigatório nos currículos, e também com a presença dos professores de Filosofia manifestação mais visível que a Filosofia terá na escola, são convidados $e$ convocados a darem respostas às leituras de mundo, percebendo-se como autores das próprias histórias, dos processos e conduções existenciais, do processo de produção das razões para si e das responsabilidades que têm para consigo.

Destaque-se o papel dos professores de Filosofia que têm primado pela defesa do caráter formador desse componente curricular. Em pesquisa recente, Masullo (2012) destaca que, apesar das difíceis condições de trabalho enfrentadas por professores de ensino médio da rede pública do estado de São Paulo, os professores de Filosofia acreditam no potencial transformador de sua disciplina nessa etapa da educação escolar: 
A análise dos conteúdos das respostas dos sujeitos pesquisados revela o apreço que eles têm pela profissão de Professor de Filosofia; no entanto, foi-nos possível notar também certa angústia, certo desânimo diante do contexto no qual sua prática se realiza na escola média paulista, como, por exemplo, baixos salários; classes superlotadas; poucas aulas na grade horária; jornada excessiva de trabalho; separação entre a concepção e a execução no currículo; segregação da categoria entre efetivos $e$ não efetivos; poucos cursos de formação contínua; $e$ infraestrutura precária. A despeito do contexto desfavorável, esses professores defendem a possibilidade do Ensino de Filosofia contribuir para a formação humana dos alunos de nível Médio e, por isso, procuram legitimar esse ensino. (MASULLO, 2012, p. 143, grifo nosso).

Estudantes são convidados, nas aulas de Filosofia, a serem autores, atores e narradores da própria história, mesmo na imprevisibilidade da vida. A metáfora da atuação, como um ator, leva a pensar na improvisação, na ação em prol da visão, do latim im - pro - vis, daquilo que também se vislumbra, se projeta. É o desejo de alcançar o que se vislumbrou que põe em marcha esta ação educativa. É o investimento de intencionalização na construção de uma história. Uma educação formadora é exatamente o que os estudantes podem vislumbrar e improvisar para si. Estabelecer a forma que eles desejam, que entendem, que vislumbram, que qualificam, com as razões que estabeleceram para isso. Por isso o pensamento crítico, especialmente o filosófico que desnaturaliza as visões de mundo, é tão significativo no currículo escolar.

Os estudantes, muitas vezes sitiados em meio a um currículo prescritivo, como se vê comumente na escola média brasileira, na qual todos os conhecimentos já estão determinados e definidos como necessários e importantes, podem investir no pensamento filosófico. O papel da Filosofia consiste também em subverter esse comando, propondo aos estudantes que eles produzam os seus próprios pensamentos e investiguem os conteúdos que lhes são transmitidos como verdades, re-valorizando o mundo, a vida, a partir de suas reflexões. 
Numa escola onde o propósito é informar ou conformar - colocar dentro da forma, a Filosofia poderá propor ao educando formar-se e até mesmo transformar-se. A força formativa é a de promover a superação dos pensamentos limitadores e enganadores para que eles não sejam vistos como totalizantes, ou como sistemas fechados.

Não há como desconsiderar a experiência concreta dos estudantes para esse intento. O propósito formativo da Filosofia não ocorre sem ela.

É por isso que me inclino a ver o ensino de Filosofia como um investimento pedagógico que visa contribuir para que os adolescentes desencadeiem um processo de ressignificação de sua experiência existencial, pois eles vivem fazendo uma contínua experiência de mundo, em todas as suas dimensões. Eles vão retirando dessa experiência e de seu contexto as significações conceituais e valorativas de que precisam para dar continuidade a sua própria existência histórica. O que se espera da formação filosófica é que essas significações sejam mais condizentes com uma existência digna, não degradada, não opressiva e não alienada, de acordo com o que a Filosofia, como saber cultural acumulado e em devir, assim as construiu e continua construindo. (SEVERINO, 2004, p. 108).

Enquanto conhecimento formativo, a Filosofia só será interessante se os jovens estudantes puderem ver-se nele, buscar nesse conhecimento um sentido pessoal da vida e das coisas. A Filosofia ficará descaracterizada em caso contrário e será identificada com um pensamento "abstrato", "teórico", como "erudição vazia" desvinculada da realidade.

Um dos riscos para o ensino de Filosofia que o tornará não formativo é que ele se apresente somente como um conjunto de informações passíveis de serem transmitidas como conhecimentos enciclopédicos. Nessa concepção de ensino de filosofia, os estudantes aprenderão uma gama de conteúdos $e$ 
acumularão uma quantidade de informações da história das filosofias, como se fossem fórmulas a decorar ou receitas a cumprir. O risco é trair a própria Filosofia ao não possibilitar o contato subjetivo com o conhecimento filosófico de modo a elaborá-lo junto com os estudantes. Nesse processo, o uso do tempo para refletir é fundamental para que o pensamento não se torne sempre superficial.

A questão da formação filosófica não é a da quantidade de conhecimentos a acumular ou explicar, mas, sim, o exercício de busca da compreensão a partir do conhecimento filosófico. É preciso que a Filosofia seja identificada e utilizada como um modo de exercício do pensamento. Gelamo (2009) apresenta este alerta ao afirmar que o que é necessário na formação filosófica é o processo reflexivo que se faz no encontro com os pensamentos dos filósofos:

Aquilo que seria fundamental para a consolidação do processo formativo - a efetivação de uma mudança de atitude do aluno em face do mundo e de si mesmo, a partir de um pensamento crítico amparado pelas reflexões despertadas no encontro de seu pensamento com o pensamento dos filósofos. (GELAMO, 2009, p. 113).

A contribuição básica para a formação humana que a escola deveria propor é a de ajudar os estudantes a conhecerem o mundo e a conhecerem o próprio conhecimento. Isso quer dizer que, além de eles serem instruídos em alguns saberes básicos, cabe à escola estimular a identificação das diversas formas de conhecimento, ser instrumento de produção e inovação de conhecimentos, avaliar a validade destes e, especialmente, os processos de produção dos conhecimentos, na sua história, economia, política e ideologia. Identificar, analisar, avaliar e propor os códigos e os saberes que leem e interpretam o mundo e a si mesmo é uma formação básica, essencial para o ser humano. Uma leitura de mundo e de si mesmo, a perseguição da verdade como critério de conhecimento, é o que deve estar na base da formação humana.

O que vem a ser essa formação? É o amadurecimento, o desenvolvimento dos estudantes como pessoas humanas. Nós nos formamos quando nós nos damos conta do sentido 
de nossa existência, quando tornamos consciência do que viemos fazer no planeta, do porquê vivemos. É claro que nós não nascemos sabendo disso, e nem chegamos aos sete anos, na escola, na estaca zero. Embora as pessoas já venham aprendendo coisas e se formando desde o nascimento, no ambiente familiar e no ambiente social, só nas instituições formais de ensino, tornadas necessárias em decorrência da complexidade das sociedades contemporâneas, essa aprendizagem e essa formação passam a ser trabalhadas de forma intencional e sistemática. O trabalho pedagógico quer dizer isso: pedagogia como prática educativa significa exatamente conduzir a criança, o adolescente, o jovem ou o adulto, quando nos ambientes escolares, no caminho da aprendizagem e da formação. (SEVERINO, 2002, p. 185).

Se o ensino se reduzir à aquisição e ao acúmulo de conhecimentos que são distribuídos nas e pelas escolas, a formação humana ficará reduzida a informar, a produzir portadores de conhecimentos a serem consumidos, ao invés de propor o ato de conhecer de forma reflexiva para enfrentar os desafios propostos pela realidade. Evoca-se aqui a $\mathrm{LDB}$, em seu Artigo $22^{3}$, que versa sobre a finalidade da Educação Básica no desenvolvimento do estudante, assegurando-lhe uma formação comum para que possa progredir no trabalho e nos estudos.

Equivocadamente, pode-se ler o prosseguimento dos estudos do estudante do Ensino Médio a partir de duas concepções pragmáticas. A primeira, com vistas à inserção direta e imediata no mercado de trabalho, o que faz com que o Ensino Médio seja considerado como um capacitador para a vida econômica, cada vez mais competitiva e exigente. A segunda, com vistas ao ingresso do estudante no Ensino Superior, como se a etapa educativa do Ensino Médio fosse um rito de passagem que prepará-lo exclusivamente para ter sucesso em exames seletivos. Nesta visão, um ensino propedêutico.

Não são esses os sentidos de formação que aqui se vislumbra para o Ensino Médio, como etapa final da Educação Básica. Como terminalidade de uma etapa deverá garantir uma formação que se consolide com base em conhecimentos

\footnotetext{
${ }^{3}$ Art. 22 - A educação básica tem por finalidades desenvolver o educando, assegurar-lhe a formação comum indispensável para o exercício da cidadania e fornecer-lhe meios para progredir no trabalho e em estudos posteriores. (BRASIL, 2010).
} 
formais, e que o estudante possa, ao final do curso, ter maior clareza, profundidade, abrangência e consciência da realidade em que vive, com suas incongruências, seus valores, suas limitações e possibilidades. Que ele também possa ter consciência de si mesmo como um ser em formação, de modo que essa não se esgote ao sair da escola e possa promover possibilidades de projeção de vida digna, de boa qualidade de sobrevivência e de existência.

Conforme afirma Severino (2006), a educação é um processo de humanização do homem e do cuidado de si através de um processo formativo que promova um aperfeiçoamento humano. A educação, segundo Severino (Ibid., p. 621): "não é apenas um processo institucional e instrucional, seu lado visível, mas fundamentalmente um investimento formativo do humano, seja na particularidade da relação pedagógica pessoal, seja no âmbito da relação social coletiva”. É uma forma de cuidado do homem, não como uma economia, de modo a evitar-lhe o desgaste, também não como a preparação de um futuro "funcionário", de modo a direcioná-lo a um saber-fazer, mas sim uma forma de cuidado que visa o desenvolvimento do humano, que vai possibilitando o aprimoramento como pessoa a partir do conhecimento e da ação, utilizando-se do próprio conhecimento que desenvolve.

Assim, a formação humana básica é esta que oferece fundamentos aos saberes que a pessoa desenvolve, como também é uma base de lançamento dessa pessoa enquanto projeto de vida. $\mathrm{O}$ conhecimento e o conhecer são $\mathrm{O}$ fundamento, firmamento e sustento da pessoa, de modo a serem usados como base de lançamento de si para além da vida escolar. O propósito do conhecimento é que a pessoa, no uso de sua inteligibilidade, sensibilidade, corporeidade, sociabilidade, moralidade, integralmente, possa buscar desenvolver projetos para si e de intervenção no mundo enquanto cidadão. Trata-se de uma consciência da pulsão da vida e da busca de razão de ser da própria existência, inserindo o sujeito no mundo e construindo-o.

A crítica que hoje se faz é a de que a formação desenvolvida na escola está, muitas vezes, em descompasso com uma formação humana, no sentido da busca de uma dignidade pessoal que se atualiza pelo processo de conhecimento 
tanto de si, como personalidade, quanto do mundo, como local do existir, a fim de realizar-se como pessoa, não só individual, mas, também, socialmente situada. Muitas vezes, várias escolas, na melhor das hipóteses, seguem sendo um espaço somente de socialização dos saberes acumulados ao longo da história, um acervo de conhecimentos, que já vêm selecionados e prontos em forma de textos, discursos ou práticas para serem apresentados segundo critérios oficiais ou a partir dos imperativos do mercado, tanto para o exercício de uma profissão quanto para formatar uma postura esperada em relação ao consumo. São saberes com os quais os estudantes pouco se identificam, como se estivessem à parte dessa história sobre a qual ouvem os relatos.

No espaço e no tempo escolar, os estudantes fazem pouco exercício com os próprios conhecimentos e anseios com o intuito de se conhecerem e ao próprio conhecimento. Analisar, refletir, compreender, confrontar e reformular os próprios conhecimentos, para agir no sentido de se formarem e de transformarem a si $e$ ao mundo em que vivem pelo uso e elaboração de conhecimentos, é uma maneira de formar pelo conhecimento. A formação humana é também uma transformação no sentido de ampliar a consciência de si, ao proporcionar a internalização e a reformulação de saberes em experiências e conhecimento significativos que orientam intenções, opções e ações.

A formação se realiza na existência de um Ser social que, ao transformar em experiências significativas os acontecimentos, informações e conhecimentos que o envolvem e envolvem suas relações, nas suas itinerâncias e errâncias aprendentes, ao aprender com o outro, suas diferenças e identificações (heteroformação/transformação), consigo mesmo (autoformação), com as coisas, os outros seres $e$ as instituições (ecoformação), emergirá formando-se na sua incompletude infinita, para saber-refletir, saber-fazer e saberser, como realidades inseparáveis, em movimento, porque constantemente desafiadas. (MACEDO, 2010, p.50).

São necessários o uso e a elaboração do conhecimento tanto como apropriação das formas de entendimento da vida, como de formulação de significações para a existência. Reitera-se, nesse sentido, o que apresenta Severino 
(2002, p. 186): “A educação é, então, uma atividade, uma prática mediante a qual buscamos aprender a praticar essa subjetividade e encontrar aí as referências para a nossa vida, para as nossas ações que constituem de fato nossa existência real". Trata-se da formação da identidade pessoal, social e cultural.

Nesse processo de formação humana, o coroamento se dá na autoformação, ou seja, na efetivação da autonomia que busca formar a si mesmo, na qual o humano se torna sujeito da própria formação. Macedo (2010, p. 58) defende que a autoformação: "implica descobrir-se a si mesmo em termos de possibilidades específicas para dar um sentido à vida a partir do que se é enquanto sujeito e do que se vive enquanto sujeito aprendente. É interrogar-se sobre a existência em vista de um projeto". A busca da formação básica escolar é que a pessoa conheça a si mesma no feixe de relações em que ela se insere e que pode buscar se relacionar.

A autonomia é um constante anseio da formação, para que a pessoa busque, por si mesma, os saberes que possam ajudá-la a viver melhor em convivência. Autonomia pode ser entendida como a autodeterminação que permita à pessoa que tome o próprio destino em suas mãos. Nessa direção, o estudante não é tratado como objeto (meio), mas como sujeito e fim em si mesmo.

A autonomia é a situação na qual agimos levando em consideração regras das quais fomos os criadores ou que, mesmo as encontrando prontas na sociedade, avaliamos como significativas $e$ incorporamos ou internalizamos em nossas ações. Ao contrário de uma situação de heteronomia - na qual a ação obedece a regras impostas externamente e aceitas passivamente, e se realiza levando-se em conta a punição ou a recompensa que se terá -, na situação de autonomia os indivíduos não deixam de levar em conta, para a sua conduta, regras ou normas, mas o fazem de acordo com princípios sobre os quais refletem $e$ que orientam seu agir. (LORIERI; RIOS, 2004, p. 65-66).

Não se trata apenas de uma autonomia intelectual, mas também e principalmente de uma autonomia pessoal e social, que proporcione ao sujeito que ele saiba e queira tomar as decisões concernentes à sua realidade e que faça $e$ 
ponha em ação um projeto de si mesmo e da vida em coletividade. Para Macedo (2010, p. 69): "Um dos sentidos fortes da educação e da formação é a construção da autonomia socialmente edificada e exercida de forma qualificada". A autonomia é uma conquista, fruto de um processo educativo que passa pelo desenvolvimento da vontade, das opções, das responsabilidades, das compreensões e do juízo, do "pensar certo".

\section{Considerações finais}

Uma ressignificação de si e da realidade produz uma ontologia e uma antropologia de modo que a pessoa entenda que o mundo é também o sentido que se dá a ele, e formular sentidos para a realidade é a contribuição que a formação filosófica apresenta para o jovem estudante do Ensino Médio. É o que Severino (2009, p. 15) propõe para o ensino de Filosofia: "Subsidiar o jovem aprendiz a ler o seu mundo para se ler nele". É uma hermenêutica crítica e criativa, como forma de conhecimento do mundo e de si mesmo, apreendendo os sentidos já dados, os contextos, as razões expressas, as a serem elucidadas, e os sentidos a serem elaborados.

É função da escola básica propiciar que os estudantes possam conhecer como se conhece, como o conhecimento é produzido, como ele é afirmado e suas consequências no poder, no mundo, no trabalho e na cidadania, tanto para si quanto para a vida em sociedade. É fundamental que os estudantes se percebam como autores de conhecimento, como pessoas críticas e criativas que buscam autonomia para saber como lidar com a vida e continuar aprendendo, buscando uma educação ao longo da vida.

É nesse sentido que a formação humana deve ser projetada e posta em ação na escola de Educação Básica e, especificamente, no Ensino Médio:

[...] o que é mais importante, com o desenvolvimento integral dos jovens que frequentam o ensino médio, no sentido de transformá-los em indivíduos conscientes, conhecedores dos problemas de seu tempo, historicamente 
situados e enriquecidos pessoal e profissionalmente, via possibilidade de enfrentar os desafios atuais e presentes, não apenas em nossa sociedade, mas também em outras instâncias, igualmente impregnadas pela competitividade, individualismo e violência. (FRANCO et. al., 2004, p. 45).

A máxima que Sócrates conheceu e assumiu para si do Oráculo de Delfos, "Conhece-te a ti mesmo", é ainda atual no que se propõe ao Ensino Médio. Tratase de um conhecimento formador, de "uma formação humana que conduz à consciência, à responsabilidade e à autodeterminação pessoal e social que conduz ao convívio, à solidariedade e à compreensão sincera da realidade". (WOGEL, 2007, p. 9).

\section{REFERÊNCIAS}

BRASIL. Lei $n^{\circ}$. 9.394, de 20 de dezembro de 1996. Estabelece as diretrizes e bases da educação nacional. 5. ed. Brasília: Câmara dos Deputados, Coordenação Edições Câmara, 2010. (Série Legislação, nº. 39).

CÁRIA, Neide Pena. A parceria de empresas educacionais de iniciativa privada com as redes municipais de educação do sul de Minas Gerais. 2012. 232 f. Tese (Doutorado em Educação: Currículo) - Pontifícia Universidade Católica de São Paulo, São Paulo, 2012.

CHIZZOTTI, Antônio; PONCE, Branca Jurema. O Currículo e os sistemas de Ensino no Brasil. Currículo sem Fronteiras, Pelotas, v. 12, n. 3, p. 25-36, set./dez. 2012.

<http://www.curriculosemfronteiras.org/vol12iss3articles/chizzotti-ponce.pdf>

Acesso em: 21 abr. 2014.

DEINA, Wanderley José. Filosofia no Ensino Médio: uma leitura com base na Teoria Crítica da Escola de Frankfurt. In: CEPPAS, Filipe; OLIVEIRA, Paula R. de; SARDI, Sérgio. A. (Orgs.). Ensino de Filosofia: formação e emancipação. Campinas: Alínea, 2009.

FRANCO, Maria Laura P. Barbosa et. al. Ensino Médio e Ensino Técnico no Brasil e em Portugal: raízes históricas e panorama atual. Campinas: Autores Associados, 2004. (Col. Educação Contemporânea).

GELAMO, Rodrigo Pelloso. O ensino de filosofia no limiar da contemporaneidade: o que faz o filósofo quando seu ofício é ser professor de filosofia? São Paulo: Cultura Acadêmica, 2009. 
LORIERI, Marcos Antônio; RIOS, Terezinha Azerêdo. Filosofia na escola: o prazer da reflexão. São Paulo: Moderna, 2004. (Col. Cotidiano Escolar).

MINEIRO, Francisco Valmir Soares. A produção acadêmica sobre o componente curricular Filosofia no Ensino Médio (2004-2013). 2015. 130 f. Dissertação (Mestrado em Educação: Currículo) - Pontifícia Universidade Católica de São Paulo, São Paulo, 2015.

MACEDO, Roberto Sidnei. Compreender/mediar a formação: o fundante da educação. Brasília: Liber Livro Editora, 2010.

MASULLO, Maria Helena. O componente curricular Filosofia e seus professores no Ensino Médio da rede estadual de educação de São Paulo. 2012. $179 \mathrm{f}$. Dissertação (Mestrado em Educação: Currículo) - Pontifícia Universidade Católica de São Paulo, São Paulo, 2012.

SEVERINO, Antônio Joaquim. A filosofia na formação do jovem e a ressignificação de sua experiência existencial. In: KOHAN, Walter. (Org.). Ensino de Filosofia: perspectivas. Belo Horizonte: Autêntica, 2002.

. O ensino de Filosofia: entre a estrutura e o evento. In: GALLO, Sílvio; DANELON, Márcio; CORNELLI, Gabriele. Ensino de filosofia: teoria e prática. Ijuí: Ed. UNIJUÍ, 2004. (Col. Filosofia e Ensino; 6).

Filosofia: guia do professor. São Paulo: Cortez, 2009. (Col. Magistério. Série Formação Geral).

A busca do sentido da formação humana: tarefa da filosofia da educação. Educação e Pesquisa, São Paulo, v. 32, n. 3, p. 619-634, 2006. Disponível em: <http://educa.fcc.org.br/scielo.php?script=sci_arttext\&pid=S151797022006000300013\&lng=es\&nrm=iso >. Acesso em: 3 jan. 2014.

A filosofia na formação do adolescente. In: HORN, Geraldo Balbuíno. (Org.). Filosofia e educação: temas de investigação filosófica. Curitiba: Juruá, 2012. (Col. Biblioteca de Filosofia e Educação Filosófica). Disponível em: $<$ http://www.educadores.diaadia.pr.gov.br/arquivos/File/deb_nre/afilosofianaforma caodoadolescente_severino.pdf. > . Acesso em: 28 abr. 2014.

PONCE, Branca Jurema. O Tempo no Mundo Contemporâneo: O Tempo Escolar e a Justiça Curricular In:

; MINEIRO, Francisco Valmir. A contribuição da produção acadêmica sobre o ensino de filosofia no ensino médio e o caráter formador indispensável desse componente curricular. Eccos, São Paulo, n. 38, out-dez 2015. No prelo. 
Revista Sul-Americana de Filosofia e Educação - RESAFE

WOGEL, Livio dos Santos. Ócio do Ofício: contribuições da pedagogia do ócio para a formação de professores. 2007. 166f. Dissertação. (Mestrado em Educação) - Instituto de Educação, Universidade Federal de Mato Grosso, Cuiabá, 2007. 